\title{
Facebook como dispositivo de vigilância e visibilidade: algumas controvérsias em questão ${ }^{1}$
}

\author{
Facebook as surveillance and visibility devices: some controversies in \\ question
}

\author{
Luciana Santos Guilhon Albuquerque ${ }^{2}$ \\ Rosa Maria Leite Ribeiro Pedro ${ }^{3}$
}

\begin{abstract}
RESUMO
Nosso trabalho pretende refletir sobre as controvérsias que giram em torno do uso das redes sociais, especialmente o Facebook, como dispositivo de vigilância e visibilidade, provocando tensões entre a preocupação com a segurança e a defesa da privacidade. Inspiradas na Teoria Ator-Rede (TAR), que aposta numa simetria entre atores humanos e não humanos na construção do social, tentamos seguir algumas pistas, por meio da leitura de notícias em jornal, a fim de retraçar as articulações entre governos, Facebook e outros atores na configuração de uma rede de vigilância e visibilidade. Tendo como referência o trabalho de Foucault sobre a disciplina, pudemos apontar algumas diferenças referentes a novas formas de controle e governo, além de refletir sobre novas formas de estabelecer a verdade do sujeito, ancoradas na exterioridade de seus atos.
\end{abstract}

Palavras-chave: Facebook. Vigilância. Visibilidade.

\begin{abstract}
Our paper discusses the controversies over the use of social networks, especially Facebook, as surveillance and visibility devices, creating tensions between concern for security and defense of privacy. Inspired by Actor-Network Theory (ANT), which focuses on symmetry between humans and non-human actors in the construction of social, we try to follow some clues, by reading newspaper articles. Our intention is to reassemble the links between governments, Facebook and other actors that constitute a network of surveillance and visibility. Foucault's work on discipline served as a reference. Thus, we could indicate some differences related to new forms of control and government, and reflect on new ways of establishing the truth of the subject, anchored in the expression of their actions.
\end{abstract}

Keywords: Facebook. Surveillance. Visibility.

\footnotetext{
${ }^{1}$ Trabalho apresentado no dia 17 de outubro de 2013, no Grupo de Trabalho 9 - Tecnologia, visualidade e subjetividade.

2 Mestre em Psicossociologia. Doutoranda Psicologia/UFRJ e Professora Assistente IBMR. E-mail: guilhonluciana@gmail.com

3 Doutora em Comunicação e Cultura. Professor Associado Psicologia/UFRJ. E-mail: rosapedro@globo.com
} 
Estimuladas por notícias recentes, publicadas no jornal O Globo (entre sete de junho e sete de julho de 2013), sobre o monitoramento de ligações telefônicas e Internet realizado pelo governo americano, com a justificativa de combater 0 terrorismo, decidimos refletir sobre as controvérsias que giram em torno do uso das redes sociais, especialmente o Facebook, como dispositivo de vigilância e visibilidade, provocando tensões entre a preocupação com a segurança e a defesa da privacidade. Neste trabalho, buscamos seguir pistas que nos serão úteis para delinear algumas dessas controvérsias.

No dia sete de junho de 2013, a reportagem "Nos passos de Bush" (BARBOSA) revela que o atual presidente dos Estados Unidos, Barack Obama, apesar de criticar seu antecessor, George Bush, deu continuidade e ampliou a operação Prism, responsável por monitorar registros telefônicos e bases de dados de nove importantes empresas que atuam na Internet (Google, Apple, Microsoft, Facebook, Yahoo, AOL, Skype, YouTube e PalTal), por meio de ordens judiciais solicitando o acesso a esses dados.

Segundo o governo americano, o objetivo da operação Prism é combater o terrorismo, identificando suspeitos, sua rede de relações e sua forma de atuação, a fim de prevenir ataques. Para alcançar esse objetivo, sua estratégia é conhecer mais sobre possíveis terroristas por meio da análise de dados fornecidos por tecnologias de comunicação. Assim, acredita que pode identificar atividades anormais, padrões de comportamento e linguagem, rede de contatos de indivíduos e instituições, antecipando futuros ataques, agindo preventivamente e impedindo sua efetivação.

Ao monitorar os rastros deixados pelos cidadãos e estrangeiros, quando utilizam telefones ou Internet para se comunicarem, o governo aposta que pode cruzar esses dados e, a partir de elementos fragmentados e desconexos, pretende estabelecer uma inteligibilidade que indique características suficientes para determinar o quanto aquele comportamento pode se tornar uma ameaça. Só não fica claro que características definem um comportamento perigoso. $\mathrm{Na}$ reportagem do dia seguinte "Teremos de fazer escolhas" (BARBOSA, 2013b), Obama afirma que ninguém está escutando as conversas, o foco não é o conteúdo nem a identificação dos indivíduos. Os dados analisados são o número de origem e destino, o tempo de duração e a localização das chamadas. 
Se conseguirmos nos desvencilhar de um olhar panorâmico e adotarmos um olhar "oligóptico", como propõe Latour (2005), ou seja, se conseguirmos nos aproximar da realidade para percebermos os detalhes dos entrelaçamentos entre seus diversos atores, podemos perceber que o governo ou o presidente não agem sozinhos. No caso americano, para que essa rede de monitoramento se estabeleça e vença algumas resistências, uma infinidade de atores precisa estar mobilizada, desde a maioria dos congressistas e juízes, até os funcionários do FBI (Federal Bureau of Investigation) e da NSA (National Security Agency), que trabalham na análise dos dados, passando pelos celulares e computadores utilizados pelos cidadãos e os softwares criados para analisar todos os dados recolhidos.

Por isso vale recorrermos à ideia de uma rede heterogênea (LAW, 1992), composta de atores humanos e não humanos, em que os objetos participam da ação e da construção do social tanto quanto os humanos. Não há um privilégio da ação por parte dos indivíduos nem se procura fundamentar qualquer análise numa intencionalidade prévia, pois os objetos também interferem na ação humana, modificando-a, produzindo efeitos de poder e assimetrias. Nesse sentido, o poder do governo americano em espionar os cidadãos está ancorado na sua capacidade de mobilizar e articular, estrategicamente, diferentes atores humanos (deputados, senadores, juízes, funcionários públicos) e não humanos (tecnologias de comunicação).

Tomando a vigilância como primeira questão de análise, podemos dizer que essa parece se constituir em uma dinâmica que se apropria da fabricação de perfis e utiliza estratégias distintas daquelas mobilizadas pelo dispositivo disciplinar, tal como analisado por Foucault (1987) no livro "Vigiar e Punir". A estratégia do poder disciplinar se pauta em tecnologias que estabelecem uma norma, um padrão de conduta ideal, que delimita claramente o limite entre normal e anormal, servindo de referência para a classificação dos indivíduos. Essa norma é tornada explícita e visível, por meio de códigos, regulamentos e práticas, enquanto o estabelecimento de perfis parece se configurar de modo mais invisível e fluido.

Fernanda Bruno (2008) analisa a diferença entre as duas lógicas, argumentando que o perfil não se refere diretamente a um indivíduo específico, mas a um conjunto de traços extraídos da análise e cruzamento dos dados fornecidos pela relação entre os indivíduos. Talvez por isso não interesse exatamente ao 
governo identificar os usuários, mas seus dados são úteis para serem associados a outros dados, pois é esse cruzamento que pode estabelecer regularidades, capazes de servir de parâmetros para identificar anormalidades e simular comportamentos futuros. Nesse sentido, o que está em jogo não é uma norma preestabelecida em regulamentos que os indivíduos precisam seguir, mas normalidades extraídas, sutil e invisivelmente, a partir do monitoramento de seus comportamentos cotidianos.

No mesmo artigo, Bruno (2008) afirma que o estabelecimento de perfis não pretende criar uma regularidade a partir de uma média, ou do que seria mais comum, e "impô-la" aos indivíduos, mas desenha múltiplas microrregularidades que expressam tendências e potencialidades. Assim, podemos pensar que o perfil encarna e ampara certa possibilidade de previsão, que se coaduna com as intenções do governo em antecipar a ação terrorista, impedindo sua efetivação, ao interceptar e intervir na ação antes que ela ocorra. Na reportagem "EUA dizem que espionagem evitou 50 ataques", o diretor da NSA afirma que esse programa de monitoramento foi usado legalmente e ajudou a evitar cinquenta ataques terroristas, mas não fica claro que intervenções foram realizadas para impedi-los.

Se num primeiro momento não interessa a identificação do usuário, uma vez traçados, os perfis servem para identificar comportamentos e indivíduos perigosos, na medida em que se constituem como "um agregado de características interpessoais que projetam tendências e padrões aplicáveis a comportamentos, personalidades, competências individuais" (BRUNO, 2008, p. 14). Essa capacidade de simular e tentar prever comportamentos futuros acaba produzindo realidades, uma vez que serve de fundamento para ações de controle e prevenção do governo.

Algumas perguntas para reflexão recaem sobre os parâmetros produzidos para se caracterizar um comportamento como perigoso, que não são tão visíveis quanto a norma estabelecida pela tecnologia disciplinar. Qual a diferença entre normal e anormal? Qual o limite entre o que pode ser considerado perigoso ou não? A partir de que elementos podemos dizer que um indivíduo pode ser um terrorista? Que características configuram um perfil a ponto de servirem de alerta para a política de segurança de um governo? Isso não parece ser muito claro nem muito estável, pois a construção de perfis tende a estar mais ligada a associações circunstanciais do que a características intrínsecas do indivíduo (BRUNO, 2008). Quando a lógica disciplinar estabelece claramente a fronteira a partir da qual é 
possível classificar um comportamento como anormal, o criminoso pode ser preso pelo seu ato. Na lógica do perfil, o terrorista é classificado como tal antes de cometer o crime, a fim de possibilitar a intervenção antecipada do governo. Que intervenções são essas, também não fica claro.

Como segunda questão de análise, tomamos o jogo entre visibilidade e invisibilidade. Cabe pensar o que ganha visibilidade e o que se mantém invisível. Quando Foucault (1987) analisou o Panóptico como dispositivo de vigilância, descreveu uma dinâmica de visibilidade organizada em torno de uma hierarquia do olhar. Quem estiver na torre central, ocupa uma posição privilegiada, pois está imune aos olhares de quem está nas celas ao redor, permanecendo numa invisibilidade, podendo ver sem ser visto. Quem está nas celas, pode ser visto por quem está na torre, mas não pode ver e comprovar quem observa e quando é observado. Essa incerteza produziria um olhar vigilante voltado para si, o próprio sujeito passaria a vigiar a si mesmo, de acordo com a Norma de quem vigia, para não ser punido.

Tendo como referência essa análise, podemos pensar que os governos têm tentado se manter na invisibilidade ao se apropriar de tecnologias de vigilância sem divulgar a população suas estratégias de monitoramento, argumentando que seriam programas ultrassecretos, cujo conhecimento público, segundo eles, colocaria em risco a própria população. Quando um ex-técnico da CIA (Central Intelligence Agency), que trabalhava para a NSA, passa documentos para um jornal (The Guardian), tornando pública essa política, põe em visibilidade aquilo que o governo americano tanto se esforçava para manter em segredo.

Segundo noticiado (Um jovem contra os EUA, 2013), Edward Snowden afirma que fez isso para que o governo americano não destrua a liberdade e a privacidade das pessoas. Independente de suas motivações, essa revelação provocou algumas reações e controvérsias: o presidente Obama, apoiado por partidários e opositores, veio a público defender e justificar seu programa de monitoramento (BARBOSA, 2013c); mais revelações de programas de espionagem de outros governos, como o do Reino Unido (Britânicos espionaram o G-20, diz 'Guardian', 2013); outros países cobram explicações dos EUA sobre o monitoramento (Espiões constrangidos, 2013); investigação criminal de Snowden 
pelo $\mathrm{FBI}$ (FBI quer que ex-técnico responda por vazamento, 2013), considerado herói por uns e traidor por outros, para citar algumas.

Essa discussão não está tão distantes de nós, brasileiros. E a principal razão não é apenas porque o Brasil também virou alvo dessa vigilância (GREENWALD; KAZ; CASADO, 2013). Segundo a reportagem do dia oito de junho (GOULART; WERNECK, 2013), a ABIN (Agência Brasileira de Inteligência) emitiu um boletim elevando o risco para a segurança dos grandes eventos (Copa, Olimpíadas), após manifestações em algumas capitais contra o aumento da passagem de ônibus. Agentes infiltrados nas manifestações identificam e monitoram os líderes por meio das informações postadas nas redes sociais, pois muitas manifestações têm sido convocadas via Facebook. Mesmo que não esteja explícito que o governo brasileiro tenha um programa como o americano, que solicita judicialmente às empresas bases de dados de seus usuários, esses dados estão disponíveis e visíveis, postados pelos próprios usuários.

Na dinâmica panóptica, o indivíduo sabe que está sendo vigiado (mesmo que não saiba exatamente quando e possa eventualmente tentar fugir do olhar vigilante), pois essa vigilância se estabelece de maneira mais acintosa, articulada a outros mecanismos disciplinares como o exercício e a punição. No caso dessa nova vigilância governamental, na maioria das vezes os indivíduos não têm a menor ideia de que estão sendo monitorados, de que seus dados produzidos enquanto falam ao telefone ou usam a Internet podem ser acessados pelo governo. Nesse sentido, cabe refletirmos sobre como essas novas tecnologias de comunicação, como o Facebook, põem em cena uma dinâmica de exposição de si, produzindo um desejo de se mostrar publicamente, de abrir sua intimidade, de forma nada coercitiva, mas pelo prazer e a sedução. E como esses dados espontaneamente expostos pelos indivíduos de repente se tornaram interessantes para o governo e usados como peças fundamentais das políticas de segurança.

De acordo com outra reportagem (RISEN; LIGHTBLAU, 2013), por conta das tecnologias de comunicação digital, como smartphones, tablets, email, mídia social e similares, o mundo cria 1,5 quintilhões de bytes de dados diariamente e esse número só tende a crescer. Diante dessa quantidade infinita de dados, o governo americano tem investido bilhões de dólares para que sua agência de espionagem (NSA) seja capaz de coletar, analisar e monitorar uma grande quantidade de dados 
produzidos por cidadãos americanos e estrangeiros ao redor do mundo em suas atividades cotidianas, como falar ao telefone, checar emails, compartilhar conteúdos em redes sociais e fazer compras pela Internet, sem que saibam sobre esse monitoramento. No entanto, não basta se aprimorar no uso dessas tecnologias; para utilizá-las, o governo teve que se articular com o congresso, a fim de aprovar leis que legitimem sua ação (Lei Patriótica, aprovada em 2001 e renovada em 2011), e com o judiciário, a fim de conseguir ordens judiciais que garantam o acesso às bases de dados, uma vez que existem alguns direitos à privacidade protegidos por lei.

Dialogando com a perspectiva da TAR (Teoria Ator-Rede), que retira dos objetos sua suposta passividade, não podemos olhar, separadamente, para as tecnologias de comunicação, em especial as redes sociais, destacando-as de suas conexões com outros atores, pois o sentido de sua ação só pode ser apreendido a partir da análise da rede a que está ligada. A ação não é individual, mas compartilhada, distribuída. Nossa análise, portanto, deve se voltar para os efeitos produzidos no momento em que o governo resolve se apropriar dos dados produzidos pelo uso banal e cotidiano do Facebook, rede social amplamente usada pelos brasileiros para se comunicar ou se expressar.

A justificativa de Obama é o combate ao terrorismo. Segundo ele (BARBOSA, 2013b), é impossível garantir o máximo de segurança e, ao mesmo tempo, preservar a privacidade dos cidadãos. É preciso fazer escolhas, ou seja, se a sociedade deseja segurança, precisa abrir mão de alguma privacidade. Não podemos afirmar que essa é uma questão já estabilizada, pois, enquanto portavozes do governo vêm a público defender seu programa de vigilância, nem todos os congressistas apóiam essa política. Além de ter que lidar com resistências dentro do Congresso e de seu próprio partido, outras vozes emergem no discurso de ONGs e jornalistas que tentam defender as liberdades civis e questionar as ações governamentais (BARBOSA, 2013a).

De acordo com outra reportagem (GALLAGHER, 2013), o enviado especial da ONU para Livre Expressão, Frank La Rue, escreveu um relatório demonstrando fortes preocupações com o avanço do uso de tecnologias de espionagem pelos Estados, uma vez que estão mais baratas e acessíveis, possibilitando uma vigilância em larga escala antes impossível. A mesma reportagem esclarece que, desde a 
derrubada das torres gêmeas em Nova lorque, no dia onze de setembro de 2001, a indústria voltada para o desenvolvimento de tecnologias de vigilância cresceu, atingindo um valor em torno de US\$ 5 bilhões de dólares por ano, tendo como principal cliente os governos ao redor do mundo.

Enquanto governos têm investido em tecnologias de vigilância, muitas vezes invisíveis para a população, e vão ampliando seu poder de monitoramento dos cidadãos, esse relatório da ONU vem defender a regulação dessa atividade para preservar o direito à privacidade e os princípios democráticos da livre circulação de ideias, embasados na Declaração Universal dos Direitos Humanos. De um lado temos o discurso pela segurança e de outro pela privacidade.

Esse fato nos leva ao artigo de John Law (1992), em que reflete sobre o processo de ordenamento. Ao invés de pensar a ordem social como um fenômeno já estabelecido e estabilizado, o autor nos ajuda a pensar nos processos e agenciamentos entre atores humanos e não humanos que vão forjando uma rede, que possa superar as resistências de seus diversos atores e sustentar determinada ordem no lugar de outra. Dessa maneira, Law nos ajuda a ver a dimensão de construção/produção presente no estabelecimento de formas do social se organizar.

Ainda nesse artigo, o autor nos chama a atenção para os efeitos de poder produzidos na articulação das redes, que vão ser mais ou menos potentes na medida em que conseguem mobilizar, com a melhor estratégia possível, um maior número de atores humanos e não humanos. Assim, voltando para o exemplo brasileiro, não podemos afirmar que a ABIN possui os mesmos recursos financeiros e tecnológicos da NSA para tratamento de dados, nem a mesma articulação com legislativo e judiciário para acessar os bancos de dados de empresas como Facebook. No entanto, ela usa as informações que estão visíveis e públicas na rede, expostas pelos próprios usuários. Podemos dizer que o uso do Facebook pelo governo vai se estabelecendo como uma estratégia para monitorar comportamentos e indivíduos que, segundo ele, podem se tornar uma ameaça à segurança pública.

Diante desse quadro, duas perguntas nos inquietam: como uma rede social, como o Facebook, pode ser considerada como fonte fidedigna de informações sobre os cidadãos para a política de segurança de um governo? Que tipo de estatuto da verdade sobre o sujeito está em jogo quando o governo supõe extrair um conhecimento sobre o comportamento dos indivíduos, por meio de informações 
fragmentadas, postadas no Facebook, e, a partir disso, classificá-los como perigosos?

Uma reflexão sobre seu surgimento pode apontar algumas direções. O Facebook foi criado por um grupo de amigos, estudantes da Universidade de Harvard, com o objetivo inicial de ajudar os alunos daquela universidade a compartilhar informações e saber mais sobre a realidade do campus, estimulando a conexão e a interação entre eles. David Kirkpatrick (2011) destrincha os percursos dessa história, relatando, em seu livro "O efeito Facebook", como essa iniciativa foi superando algumas resistências e problemas com a direção da universidade ao mesmo tempo em que se tornava popular entre os alunos, até conseguir apoio de investidores para se ampliar e ganhar o mundo.

Sem querermos esmiuçar as origens do Facebook, cabe refletir sobre as diferentes formas de interação com esse dispositivo, que foram se forjando ao longo do tempo, para além da intenção inicial de ser simplesmente uma ferramenta a fim de manter as pessoas conectadas, ajudando-as a compartilhar informações. Segundo Kirkpatrick (2011), desde o início a equipe criadora do Facebook sempre teve a preocupação em criar um ambiente virtual onde os usuários se sentissem seguros e à vontade para se expor, partilhando informações que correspondessem à realidade. Uma vez que o foco era aprimorar a interação entre pessoas que se conheciam, não faria sentido inventar características sobre si que não fossem fidedignas, pois seriam facilmente confrontadas fora do mundo virtual.

Essa preocupação com um ambiente seguro parece ainda estar presente. Apesar das denúncias de fornecimento de dados pelo Facebook ao governo americano, Mark Zuckerberg, criador e CEO da empresa, negou que alguma vez tenha recebido pedido ou ordem judicial de qualquer agência governamental com solicitação de informação ou metadados (Espionagem americana preocupa europeus, 2013). Isso poderia comprometer a confiança que os usuários teriam em relação à segurança do ambiente dessa rede social, inibindo sua exposição e compartilhamento de informações. Mas isso não é certo, pois uma pesquisa aponta que a maioria da população americana (56\%) considera aceitável o monitoramento de dados pela NSA para combate ao terrorismo (BARBOSA, 2013b).

Independente do repasse dessas informações ser verdadeiro, o que poderia se configurar como uma ameaça à privacidade, ele não é fundamental para que a 
vigilância governamental se realize. Se nos atermos ao caso brasileiro, a ABIN se apropria de informações privadas tornadas públicas pelos próprios usuários, provavelmente porque aposta que são verdadeiras. Diante disso, podemos pensar que o Facebook foi se configurando como uma plataforma virtual de interação que não se opõe à realidade, mas performa realidades ao dar visibilidade a atitudes, ações, opiniões, pensamentos antes partilhadas, quando partilhadas, em grupos de menor dimensão. A dinâmica dessa rede social parece incitar e favorecer a exposição de si.

Para participar da rede e interagir é preciso se expor e podemos observar que há pessoas que são mais comedidas em sua exposição, usando algumas ferramentas para proteger sua privacidade, partilhando opiniões e gostos com amigos selecionados, enquanto outras são mais diretas ou excessivas na "publicização" de si, expondo detalhes mais íntimos de vida, abolindo mais fortemente qualquer fronteira entre público e privado. Um conteúdo tão vasto de características individuais logo chamou a atenção de empresas, que se utilizaram dessas informações para realizar propagandas personalizadas, com a intenção de serem mais eficazes (KIRKPATRICK, 2011). E mais recentemente esses dados pareceram interessar os governos, como fonte privilegiada de informações sobre as atitudes dos cidadãos.

Baseando-se na análise do que Foucault chamou de governamentalidade, podemos dizer que as práticas de governo e controle foram se articulando com tecnologias mais sofisticadas, tornando-se mais heterogêneas e complexas (PEDRO, 2008). Nossa reflexão leva a crer que uma dessas tecnologias é o Facebook, justamente por tornar visíveis informações sobre os indivíduos que ajudam o governo a traçar perfis e monitorar seus movimentos.

No atual contexto brasileiro, de expectativa para os grandes eventos, a segurança pública se torna um tema estratégico para o governo. As recentes manifestações nas ruas de cidades por todo o país, que começaram com o Movimento pelo Passe Livre, reivindicando o transporte público gratuito, e se espalharam como um vírus, não apenas, mas também, por causa do Facebook e seu poder de contaminação, acabaram se tornando foco de monitoramento por terem sido consideradas uma ameaça à segurança (GOULART; WERNECK, 2013). 
A visibilidade propiciada por essa rede social possibilitou o crescimento desse movimento ao mesmo tempo em que torna seus líderes vulneráveis ao monitoramento do governo. Ao utilizarem o Facebook para se mobilizar politicamente, os líderes desse movimento dão visibilidade a seus anseios, contrapondo-se às políticas do governo e constituindo-se como uma ameaça em potencial à ordem nas ruas, necessária para a realização pacífica dos grandes eventos. Nesse sentido, a visibilidade proporcionada pelo Facebook pode servir a diversos e controversos interesses, dependendo dos atores que se articulam a ela. Se por um lado pode servir de instrumento de monitoramento governamental, por outro lado, os vídeos compartilhados no Facebook após a manifestação do dia vinte de junho no Rio de Janeiro pareciam querer dar visibilidade a uma versão da realidade diferente do que estava sendo e foi veiculado pela mídia televisiva, que construiu uma narrativa dos fatos focando em cenas de violência, cujos autores foram classificados de vândalos.

No Brasil, a mídia televisiva possui um grande alcance e produz uma narrativa dos fatos que se torna hegemônica, na medida em que a maioria dos veículos constrói discursos sobre a realidade muito similares. Dessa maneira, aquilo que era apenas uma versão se torna a "realidade de fato". Acompanhando os desdobramentos no Facebook das manifestações no Rio de Janeiro do dia vinte de junho, foi possível assistir a uma grande quantidade de vídeos mostrando a violência policial. Esses vídeos foram feitos por indivíduos comuns, por meio de seus celulares e câmeras, postados e compartilhados imediatamente, fornecendo outra narrativa dos eventos. Mesmo se ponderarmos sobre o alcance dessa visibilidade produzida, em termos de quantidade de pessoas que tiveram acesso a essas imagens, um dos efeitos foi a mudança do discurso televisivo no dia seguinte, abordando a violência policial na repressão aos manifestantes, sem se restringir a exibir apenas a violência de quem estava se manifestando. A questão sobre a origem do embate entre manifestantes e policiais continua sendo uma controvérsia.

Por fim, gostaríamos de terminar esse trabalho com uma reflexão sobre o estatuto de verdade do sujeito que pode estar em jogo quando o governo resolve usar a visibilidade do Facebook para vigiar os indivíduos. Diferente dos dispositivos disciplinares que ajudaram a produzir a ideia de uma verdade interiorizada, alcançada pela atividade reflexiva e práticas confessionais, dispositivos como o 
Facebook ajudam a produzir uma ideia de verdade de si sustentada na exterioridade, no que está visível. Nesse sentido a subjetividade vai se constituindo na possibilidade de se fazer visível ao outro (BRUNO; PEDRO, 2004).

Então, talvez, a questão não seja tanto defender ou não o direito à privacidade, pois poderíamos pensar que foi um valor construído em determinado momento de nossa história e, como tal, pode perder seu valor num mundo em que as pessoas cada vez mais se expõem sem constrangimentos, em que esse desejo de se mostrar vem sendo produzido. A questão parece ser problematizar os efeitos dessa exposição, do perigo que pode ser supor chegar à verdade do sujeito através dos traços, gostos e opiniões que expõe nas redes sociais. E problematizar a produção de uma lógica em que a verdade do sujeito poderia ser inferida a partir da análise de fragmentos de seu comportamento e da antecipação de seus atos.

De maneira alguma nossa intenção é apontar como enganadora essa versão sobre o sujeito e defender que a verdade de si se dá no interior de cada psiquismo, uma vez que apostamos que a verdade é produzida. O que nos interessa problematizar, com esse trabalho, são os efeitos de controle e resistência engendrados a partir do momento em que se supõe que a verdade de cada um pode ser extraída do cruzamento de seus dados mais explícitos.

Nesse sentido, cabe pensar no quanto o uso de redes sociais como o Facebook nos ajuda a banalizar e naturalizar a exposição de si como prática cotidiana. E cada vez que nos expomos, voluntariamente ou não, fornecemos material para sermos vigiados, por meio de um controle que se efetiva, principalmente, pela antecipação da ação. O que está em jogo nessa lógica não é tanto o que somos ou fazemos, mas o que podemos nos tornar ou fazer. Enquanto a dinâmica disciplinar encena uma relação moral consigo, baseada numa atividade reflexiva, num mergulho em si mesmo, a lógica do controle, como bem nomeou Deleuze (1992), parece encenar uma relação de monitoramento de si, de vigilância constante de nossas atitudes, a fim de atingir no futuro a melhor performance possível. Curiosamente - e talvez não por acaso - já existem manuais de etiqueta sobre como usar o Facebook (SANTOS, 2013), ensinando a melhor maneira de construir uma boa imagem de si. 


\section{REFERÊNCIAS}

BARBOSA, Flávia. Nos passos de Bush. O Globo. Rio de Janeiro, 07 jun. 2013a. Mundo, p. 31.

. 'Teremos de fazer escolhas'. O Globo. Rio de Janeiro, 08 jun. 2013b. Mundo, p. 36.

31. Blindado no Congresso. O Globo. Rio de Janeiro, 12 jun. 2013c. Mundo, p.

Britânicos espionaram o G-20, diz 'Guardian’. O Globo. Rio de Janeiro, 17 jun. 2013. Mundo, p. 24.

BRUNO, Fernanda G.; PEDRO, Rosa. Entre aparecer e ser: tecnologia, espetáculo e subjetividade contemporânea. Intexto, Porto Alegre: UFRGS, v. 2, n. 11, julho/dezembro 2004, p. 1-16.

BRUNO, Fernanda G. Monitoramento, classificação e controle nos dispositivos de vigilância digital. Revista FAMECOS, Porto Alegre, $n^{\circ} 36$, ago. 2008, p. 10-16.

DELEUZE, Gilles. Conversações. Trad. por Peter Pál Pelbart. Rio de Janeiro: Editora 34, 1992.

Espiões constrangidos. O Globo, Rio de Janeiro, 18 jun. 2013. Mundo, p. 26.

Espionagem americana preocupa europeus. O Globo, Rio de Janeiro, 08 jun. 2013. Mundo, p. 37.

EUA dizem que espionagem evitou 50 ataques. O Globo, Rio de Janeiro, 19 jun. 2012. Mundo, p. 32.

FBI quer que ex-técnico responda por vazamento, Folha de S. Paulo, 14 jun. 2013. Mundo, p. A18.

FOUCAULT, Michel. Vigiar e Punir: nascimento da prisão. Petrópolis, Vozes, 1987.

GALLAGHER, Ryan. Poder de vigilância é perturbador. O Globo, Rio de Janeiro, 07 jun. 2013. Mundo, p. 32.

GOULART, Gustavo; WERNECK, Antônio. Após protestos coordenados, Abin eleva risco para grandes eventos. O Globo, Rio de Janeiro, 08 jun. 2013. País, p. 08.

GREENWALD, Glenn; KAZ, Roberto; CASADO, José. Na teia da espionagem. 0 Globo, Rio de Janeiro, 07 jul. 2013. Mundo, p. 36.

KIRKPATRICK, David. O efeito Facebook. Rio de Janeiro: Intrínseca, 2011. 